\title{
Free-Living Nematodes as Pollution Indicator in Incomati River Estuary, Mozambique
}

\author{
Mthobisi Innocent Soko*, Thomas Kwadwo Gyedu-Ababio \\ Inkomati-Usuthu Catchment Management Agency, Mbombela, South Africa \\ Email: *sokom@iucma.co.za; thomasga@iucma.co.za
}

How to cite this paper: Soko, M.I. and Gyedu-Ababio, T.K. (2019) Free-Living Nematodes as Pollution Indicator in Incomati River Estuary, Mozambique. Open Journal of Ecology, 9, 117-133. https://doi.org/10.4236/oje.2019.95010

Received: March 1, 2019

Accepted: May 12, 2019

Published: May 15, 2019

Copyright $\odot 2019$ by author(s) and Scientific Research Publishing Inc. This work is licensed under the Creative Commons Attribution International License (CC BY 4.0).

http://creativecommons.org/licenses/by/4.0/ (c) (i) Open Access

\begin{abstract}
Four sites following the salinity gradient of the Incomati River Estuary E1 (0-3NST), E2 (3-5NST), E3 (6-18NST) and E4 (19-27NST) were selected for the study. The aim of the study was to use free-living marine nematodes as pollution indicators in an area strongly affected by anthropogenic activities. Multivariate statistical analyses were used to determine the relationship between different environmental factors and with free-living marine nematodes. Metals such Cadmium, Colbat, Chromium, Copper, Iron, Manganese, Nickel, Vadium, Zinc and Aluminium influenced the diversity and density of free-living nematodes. Shannon-Wiener Diversity, Maturity Index and colonize-persisters percentage $(\mathrm{c} \%-\mathrm{p} \%)$ were found to be good tools for use as pollution indicators in the study. Nematode genera such as Terschellingia, Theristus and Halalaimus were found to be dominant at a site strongly impacted by both metals concentration and organic matters. The three genera are believed to be good indicators of pollution in the Incomati River Estuary. It is recommended that further studies are done along the Mozambican Coast to identify nematodes that can be used as pollution indicators.
\end{abstract}

\section{Keywords}

Estuary, Nematodes, Chlorophyll-a, Metals, Organic Matter, Pollution

\section{Introduction}

The Incomati River Estuary is prone to anthropogenic activities such as agricultural and industrial effluents from the upper catchments of the Incomati Basin. The presence of impoundments and abstraction taking place in the upper catchment reduces the flow regime, therefore, resulting in sediments fluxes. These activities affect the estuarine environment by changing the habitat structure and dynamics of living communities [1] [2]. These further affect the estua- 
rine ecosystem and other goods and services rendered by the estuary [3]. The main disturbances in an estuarine and marine environment are organic pollution and sediment [4].

To understand the environmental quality of estuaries, free-living nematodes provide advantages as biological indicators because of their morphological structures such as mouth structure, tail shape and length-width ratio which relate to ecological functions [5] [6] [7] [8]. Their diversity in aquatic environment and their response to pollution make them a good tool in studies of environmental pollution [9] [10]. Nematodes were used in studies conducted in temperate estuarine and marine environment, and showed to be good pollution indicators for induced disturbance. Thus, they have indicated their importance in marine environment [11] [12] [13] [14]. In studies conducted in tropical estuaries in Tunisia and South Africa nematodes were also found to be sensitive to pollution disturbance [15] [16] [17].

The distribution and environmental factors affecting free-living nematodes are the main information in understanding the ecology of their communities and the role in dynamics of the ecosystems. There is no enough evidence of the availability of a specific factor such as grain size or organic content of sediment that contributed to the distribution patterns of nematodes [18]. Instead, nematodes respond to complex setting of environmental factors such as food availability, salinity and grain size [19] [20] [21] [22]. Sediment characteristics such grain size analyses, grain shape, sorting and pores space influence the diversity and abundance of nematodes in a soft bottom environment [23] [24]. Median grain size of sediments has been found to be the primary influence on meiofaunal density and diversity [11] [25]. In a case study conducted in the Swartkops River system, in South Africa, nematodes distribution was found to be attributed to food distribution patterns and other factors such as organic carbon and chlorophyll-a [15]. The aim of this study was to use free-living marine nematodes as pollution indicators in an area strongly affected by anthropogenic activities.

\section{Materials and Methods}

\subsection{Study Area}

The Incomati River Estuary is about 40 - $50 \mathrm{~km}$ long and meanders within the coastal plain. It is located on the east coast of Africa, Southern Mozambique (Figure 1) and the main anthropogenic activities along the estuary are drylands crops such as maize, grazing, sugarcane, vegetables and citrus [26]. Four sites were selected from the Incomati River Estuary following the salinity gradient of the estuary and based on their prone to pollution (Table 1).

\subsection{Free-Living Nematodes}

The study was conducted from June 2017 to April 2018. Sampling was done during low tide in the subtidal region using a hand held perspex corer which was $1 \mathrm{~m}$ long and $3.6 \mathrm{~cm}$ diameter down to a depth of $10 \mathrm{~cm}$. Most nematodes are 
Table 1. Sites selected for meiofauna in the Incomati Estuary from June 2017 to April 2018.

\begin{tabular}{ccccc}
\hline \multirow{2}{*}{ Site Names } & Salinity Ranges & Estuarine Zone & \multicolumn{2}{c}{ Co-ordinates } \\
\cline { 4 - 5 } & & & Latitude & Longitude \\
\hline E1 & $0-3$ NST & Oligohaline & -25.7198611 & 32.6982694 \\
E2 & $3-5$ NST & Euhaline & -25.733775 & 32.680644 \\
E3 & $5-18$ NST & Mesohaline & -25.7622361 & 32.729275 \\
E4 & $18-27$ NST & Polyhaline & -25.8324361 & 32.73435 \\
\hline
\end{tabular}

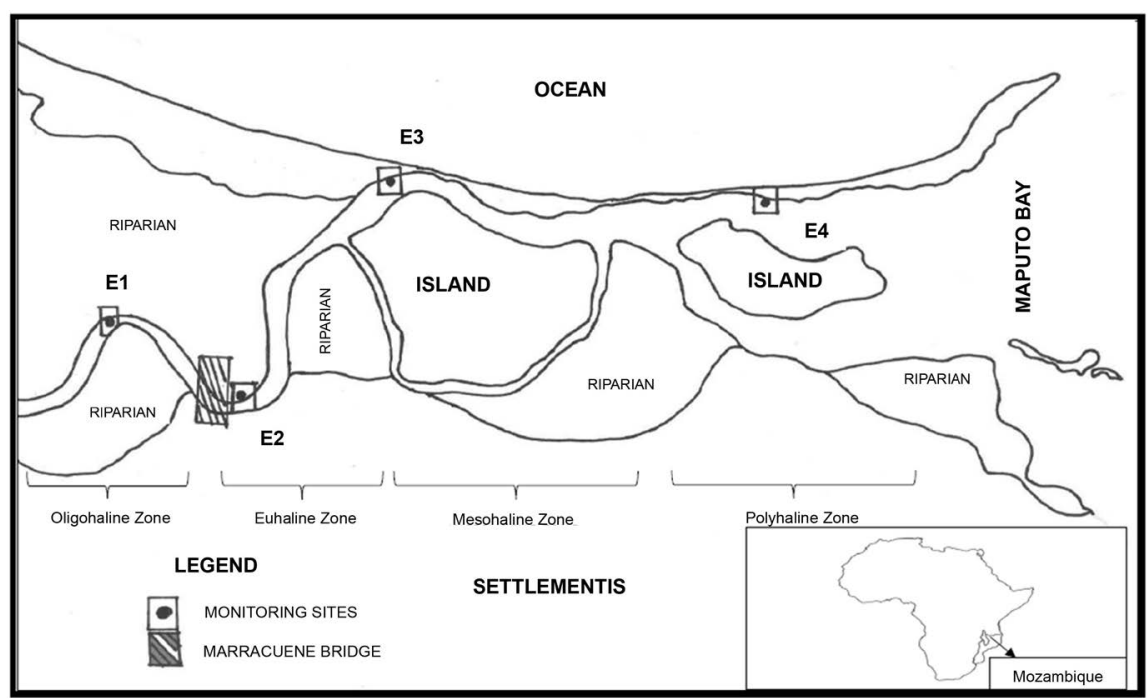

Figure 1. Map showing the monitoring sites in the study area.

mostly found between $4 \mathrm{~cm}$ to $10 \mathrm{~cm}$ of the sediment [27] [28] [29] [30]. One of the two samples taken at each site bi-monthly from June 2017-April 2018 was used for free-living nematodes analysis. Before sediment samples were taken, the sediments in the container was treated with $6 \% \mathrm{MgCl}_{2}$ on the field to facilitate relaxation of the meiofauna. In the laboratory the meiofauna in the sediment samples were fixed with $5 \%$ formalin with Bengal Rose solution added for staining of the nematodes. Meiofauna were separated from sediment using a centrifugal method with sucrose solution [31] [32] [33]. Nematodes were then collected in $5 \%$ formalin and counted under a stereo microscope at $40 \times$ magnification using counting petri-dish [34]. The first hundred counts of specimens in each replicate were randomly selected and mounted in wax ring slides for identification using pictorial keys [35]. Nematodes feeding types were investigated using their morphological structure [36].

\subsection{Environmental Factors}

The other corer sample was used for the analysis of Metals, Particle Size, Organic Matter and Chlorophyll-a. Sediment particle size and Organic Matter analysis were done following the procedure set by [37] [38]. Metal analysis was done fol- 
lowing the procedure set by [15]. A method/procedure set by [39] was used for the analysis of Chlorophyll-a.

\section{Data Analysis}

A PRIMER 6.0 which is a multivariate statistical package developed by Plymouth Marine Laboratory [40] was used for the analysis of free-living nematodes data. A Shannon-Wiener Diversity Index was to determine the diversity of nematodes, while a Non-Multidimensional Scaling and Brait-Curtis Cluster Analysis were used to determine the similarities between the sites sampled based on their nematodes diversity, density and sediment particle sizes. The significant difference between sites was tested using a two-way ANOVA or PERMANOVA. A $\mathrm{K}$-dominance curve was plotted for the comparison of genera composition at the sites. An RDA plot was done to determine the relationship between different environmental variables with nematode feeding types. A BIOENV procedure using a spearman's correlation was used to determine the relationship between environmental variables and the structure of nematodes community [41]. A Maturity Index was used to analyse the life strategy on free-living nematodes [42] [43] and a value on a scale (c-p score) was assigned to nematodes genera. The Maturity Index formular

$$
\mathrm{MI}=\sum_{i=1}^{n} v(i) \cdot f(i)
$$

was used to calculate the weighted average of the individual colonizer-persisters $(c-p)$ values. The following symbols in the formular: $v(i)$ represented the $c-p$ value of the taxon, then $i$ and $f(i)$ was the frequency of that taxon.

\section{Results and Discussions}

\subsection{Sediments}

A variation of sediment particle sizes was found in the four sites sampled in the Incomati River Estuary (Figure 2). Site E1 was characterised mostly by fine sand with $46.32 \%$ and this was attributed to deposition taking place at the site.

Site E3 and E4 were mostly characterised by coarse and very coarse particle sizes which were attributed to tidal action that washes the sand from small particles. Sediment grain sizes are important environmental factor especially that help in the structuring of meiofauna.

\subsection{Organic Matters}

The highest percentage of Organic Matter was found at site E2 with a mean value of $2 \%$ (Figure 3). The highest percentage of Organic Matter was attributed to fine sand particles because they have higher surface area for organic adsorption. Similarly, in a study conducted in Southern European estuaries organic matters were higher at sites characterised by fine particle size [44].

The lowest percentage of Organic Matters was found a site E1with a mean value of 1.2\%. At both sites E3 and E4, the mean percentage of Organic Matters 


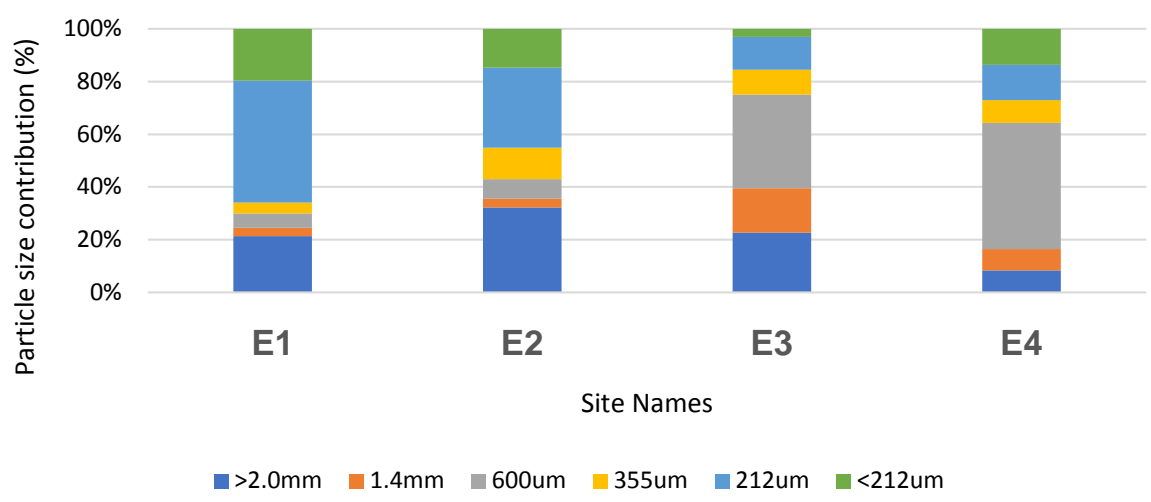

Figure 2. Sediments particle size analysis in the Incomati River Estuary.

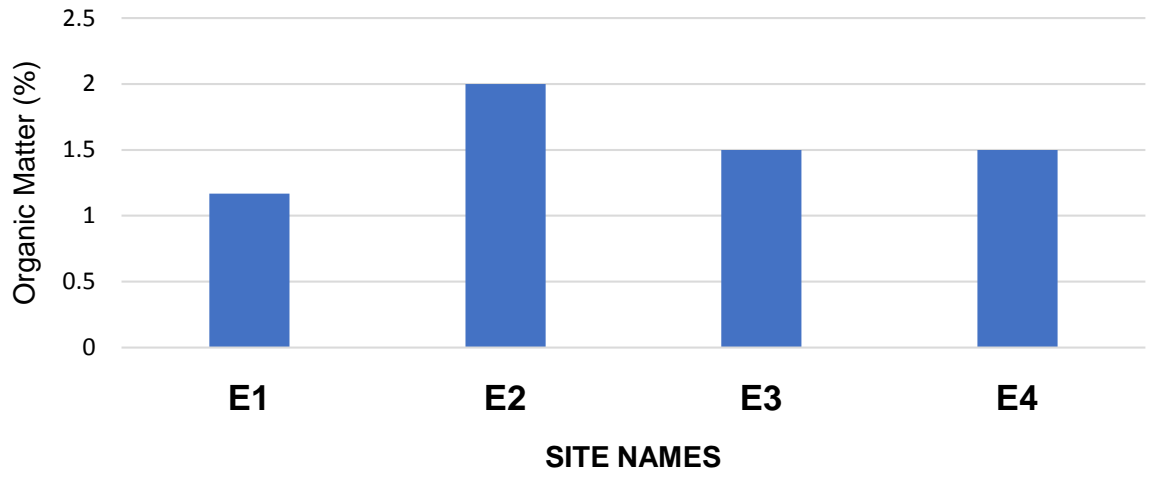

Figure 3. A graph representing the Organic Matter concentration in the Incomati River Estuary.

was $1.5 \%$. A two-way ANOVA indicated that there was no significant different ( $p>0.05$ ) of Organic Matter concentration between the sites sampled.

\subsection{Chlorophyll- $a$}

The highest concentration of Chlorophyll-a was found at site E3 with a mean concentration value of $3.2 \mathrm{mg} / \mathrm{m}^{3}$ (Figure 4).

The second highest concentration of Chlorophyll-a was found at site E4 with a mean concentration value of $1.24 \mathrm{mg} / \mathrm{m}^{3}$. The lowest concentration of Chlorophyll-a was found at site E2 and E1 with a mean concentration of $0.87 \mathrm{mg} / \mathrm{m}^{3}$ and $0.95 \mathrm{mg} / \mathrm{m}^{3}$ respectively.

\subsection{Metals}

Ten metal concentrations (Cadmium, Colbat, Chromium, Copper, Iron, Manganese, Nickel, Vadium, Zinc, and Aluminium) were found (Table 2) in the estuary. The highest concetration of metals were observed at site E2, and the second highest concetration was observed at site E1. Site E2 is situated in the Euhaline Zone while site E1 is situated in the Oligohaline Zone. The lowest concetration was observed at site E4 and E3, which were situated in the Polyhaline and Mesohaline Zones respectively.

PERMANOVA analysis indicated that there was a significant different $(\mathrm{p}<0.05)$ 


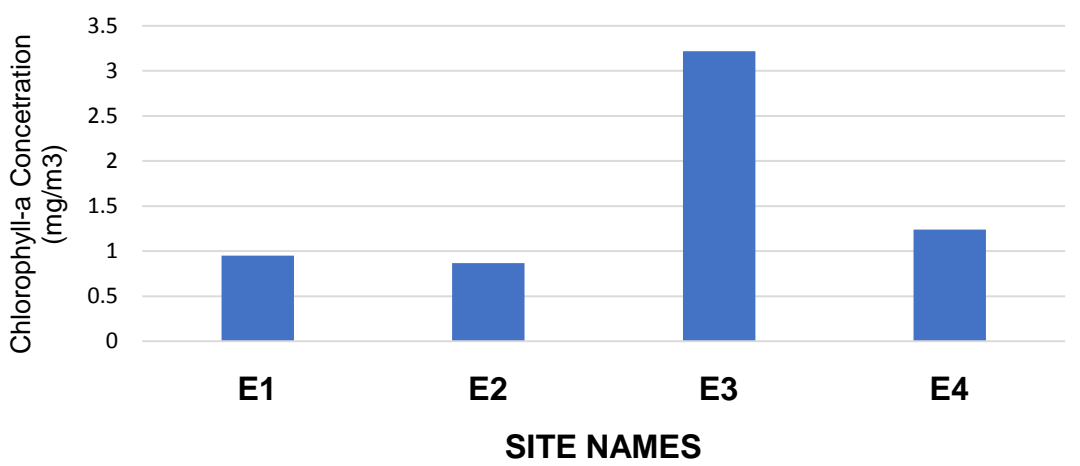

Figure 4. Chlorophyll-a concentration in the Incomati River Estuary.

Table 2. Mean concetration of metals from sediments sampled from June 2017 to April 2018.

\begin{tabular}{ccccc}
\hline Metals (ppm) & E1 & E2 & E3 & E4 \\
\hline $\mathrm{Cd}$ & 0.13 & 0.17 & 0.11 & 0.09 \\
$\mathrm{Co}$ & 3.27 & 3.89 & 1.61 & 0.49 \\
$\mathrm{Cr}$ & 10.28 & 14.92 & 20.05 & 7.87 \\
$\mathrm{Cu}$ & 5.25 & 7.85 & 4.37 & 4.10 \\
$\mathrm{Fe}$ & 4354.83 & 9125.12 & 2777.83 & 1537 \\
$\mathrm{Mn}$ & 123.67 & 194 & 54.83 & 59.67 \\
$\mathrm{Ni}$ & 8.38 & 11.97 & 3.45 & 3.57 \\
$\mathrm{~V}$ & 6.87 & 12.30 & 4.28 & 1.43 \\
$\mathrm{Zn}$ & 13.68 & 12.6 & 6.75 & 8.88 \\
$\mathrm{Al}$ & 4802 & 7935.33 & 2264.67 & 904.17 \\
\hline
\end{tabular}

between sites sampled, but not between months. These results indicated that the concentration of metals changes spatial, but not temporal. The higher concentration of heavy metal in the study area especially at sites E1 and E2 was attributed to different anthropogenic activities from the upper catchments, and local informal settlements.

\subsection{Nematodes Density}

A total of 5989 nematodes individuals $/ 10 \mathrm{~cm}^{2}$ were sampled in the Incomati River estuary. The highest nematode density of 2605 individuals $/ 10 \mathrm{~cm}^{2}$ was found at site E4 which is situated in the Polyhaline Zone of the estuary, while a lowest density of 721 individual $/ 10 \mathrm{~cm}^{2}$ was found at site E1 situated in the Oligohaline Zone (Figure 5). These findings indicated that nematodes density decrease with decrease in salinity.

Similarly, in a study conducted in the Swartkops River System, South Africa [15], nematodes density was found to be higher in the Polyhaline Zone and lower in the Oligohaline Zone. Different findings were observed in another study conducted in Mondego estuary [45]. A two-way ANOVA indicated a significant different $(p<0.05)$ of nematodes density between the sites. 


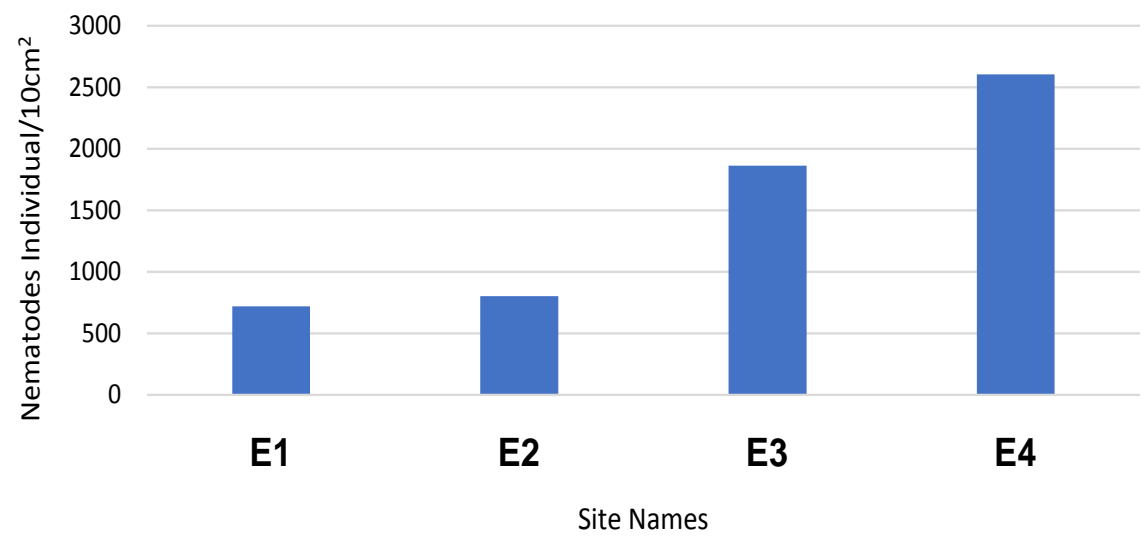

Figure 5. Mean nematodes density sampled in the Incomati River Estuary.

\subsection{Nematode Diversity}

A total of 35 nematode genera were found in the Incomati River Estuary (Appendix A: Table A1). The diversity of nematode in the Incomati River Estuary were found to differ from site to site. The lowest diversity of nematodes was found at site E1 with nematodes diversity range of 4 - 13 genera. Nematodes genera such as Haliplectus and Axonolaimus were found to be dominant at site E1 with nematodes diversity values of $41 \%$ and $13.2 \%$ respectively. The number of diversity genera at $\mathrm{E} 2$ was found to range from 4 to 12 genera, and the dominant nematodes genera were found to be Terschellingia and Theristus with $47.5 \%$, and 20.8\% respectively. Other nematode genera that were present at site E2 were Axonolaimus, Sabatiera, Daptonema, and Parodontophora which may indicate pollution and disturbance [43] [46] [47] [48]. Therefore, dominance of nematode genera such as Axonolaimus, Terschellingia, and Theristus at sites E1 and E2 indicated that these sites were more polluted than the other sites. Theristus has been found to be a good pollution indicator of organic matter [17]. Pollution at these sites was attributed to agricultural, industrial activities from upstream catchments, and informal settlements along these sites. Nematode density at site E3 ranged 11 to 18 and the dominant genera was Sabatiera with $8.5 \%$, and Theristus with $8.2 \%$ of the total nematodes genera. Site E4 had the highest diversity of nematodes with a range of 13 to 21 . The highest diversity of nematodes at site E4 and the lowest diversity of nematodes at site E1 indicated that nematodes diversity decreases from the Polyhaline zone to the Oligohaline Zone.

\subsection{Maturity Index and Shannon-Diversity Index}

The Maturity Index (MI) which is a potential indicator of nematode assemblage under stress and the Shannon-Diversity Index of the four sites sampled were calculated (Figure 6). The MI values for sites E3 situated in Mesohaline Zone, and E4 situated in Polyhaline Zone were 2.67 and 2.66 respectively. The higher value of Maturity Index at these sites indicated that nematode genera were not under stress.

At sites E2 and E1 the Maturity Index were found to be lower with Maturity 


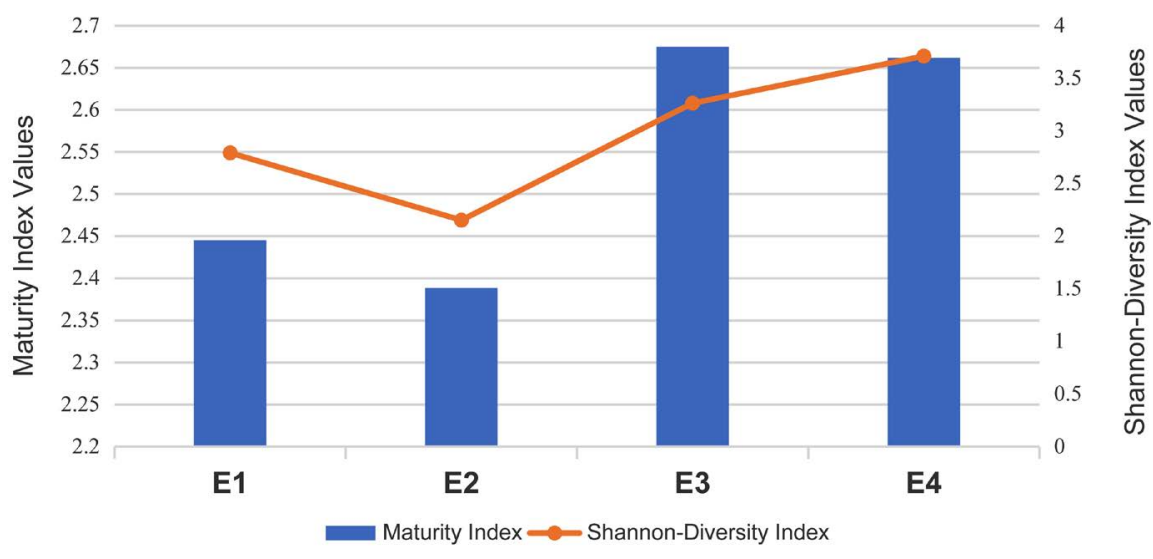

Figure 6. Maturity Index results indicating the polluted sites with Shannon-Diversity Index superimposed.

values of 2.38 and 2.44. The lower Maturity Index indicated that these sites were under stress, especially at site E2 which had higher concentration of heavy metals and total phosphate throughout the sampling period. Similarly, the Shannon-Diversity Index indicated the same finding as the Maturity Index.

A Bray-Curtis Cluster Analysis and NMDS ordinations (Figure 7(A) and Figure $7(B)$ ) indicated a group formation of sites at similarities $50 \%$ and $65 \%$. Group 1 was formed by sites E1 and E2 and group 2 was formed by sites E3 and E4 at similarity $50 \%$. The similarities within the groups were attributed to similar meiofauna taking place and experiencing similar environmental factors within the sites.

Group 3 was formed by sites E3 and E4 at similarity 65\%. The similarity at $65 \%$ indicated that the was no much change of meiofauna diversity and density at these sites, while the dissimilarities of sites E1 and E2 was attributed to the factors that these sites received different environmental factors, and meiofauna diversity changed at different period of sampling.

The K-dominance curve (Figure 8) indicated that at cumulative dominance of $40 \%$ Haliplectus dominated the nematodes communities at site E1. At a cumulative dominance of above $40 \%$ the $\mathrm{K}$-dominance indicated that Terschellingia and Theristus were the dominant genera at site E2. The dominance of these nematodes at sites E2 and E1 indicated that they were tolerant to higher concentration of metals and organic matters at these sites, hence the dominance of single genera in polluted sites.

At both sites E3 and E4, the cumulative dominance was below 20\% indicating that these sites were more diverse than sites E1 and E2. The K-dominance curve showed that the higher the salinity the lower the dominance of individual genera, and the higher the diversity of individual genera.

An RDA triplot indicated that the lower diversity and density of nematodes at site E2 was attributed to high concentration of metals such as Cadmium, Colbat, Chromium, Copper, Iron, Manganese, Nickel, Vadium, Aluminium and Organic Matters with had strong correlation with nematode feeding type 1B (Figure 9). 


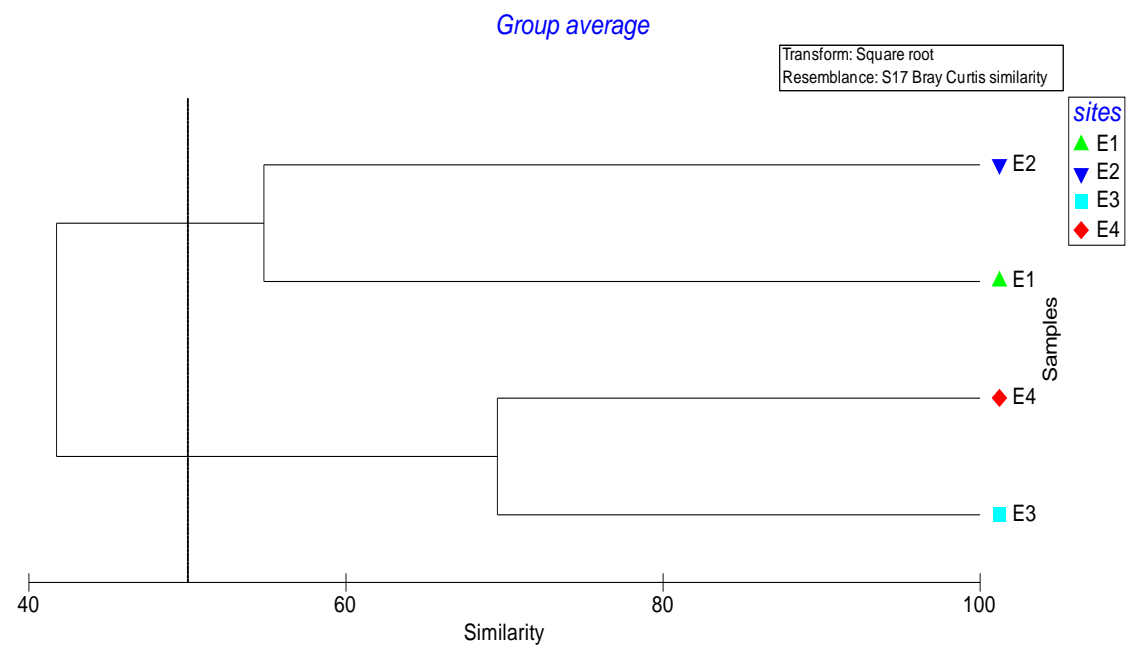

(A)

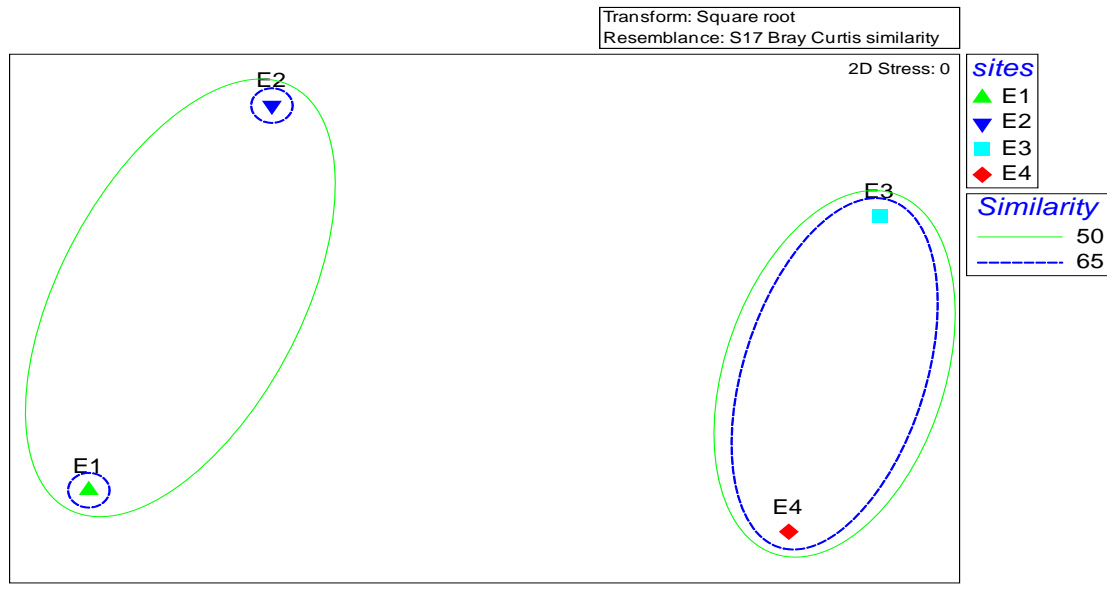

(B)

Figure 7. Bray-Curtis similarity matrix-based cluster analysis (A) and two-dimensional representation of the NMDS ordination (B) of free-living nematodes genera collected in the Incomati River Estuary. The NMDS ordination was completed with 25 iterations and showed a stress of zero.

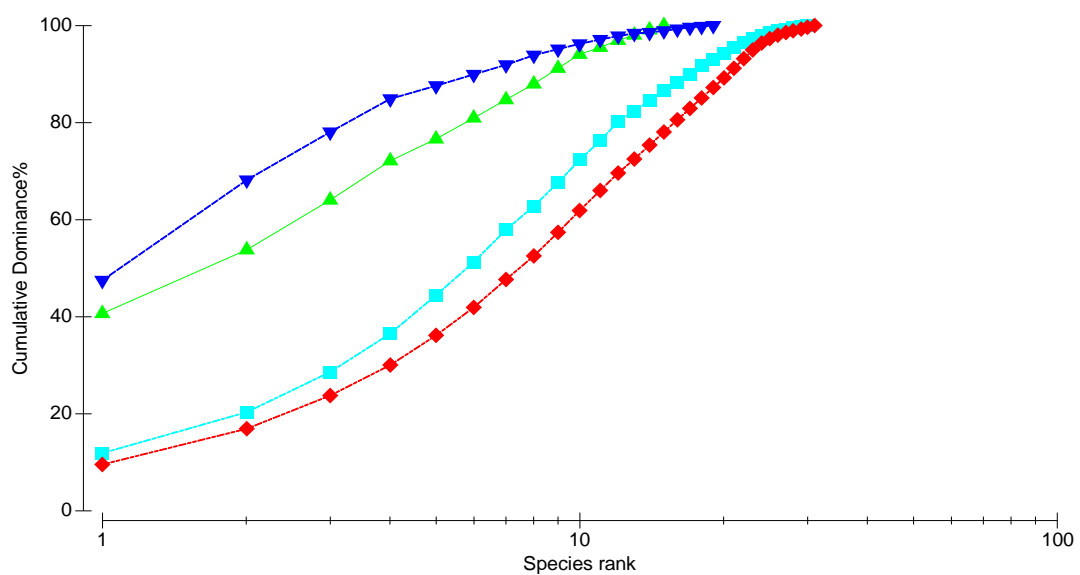

Figure 8. Ranked species K-dominance curves for the free-living nematode genera identified at the Incomati River Estuary. 


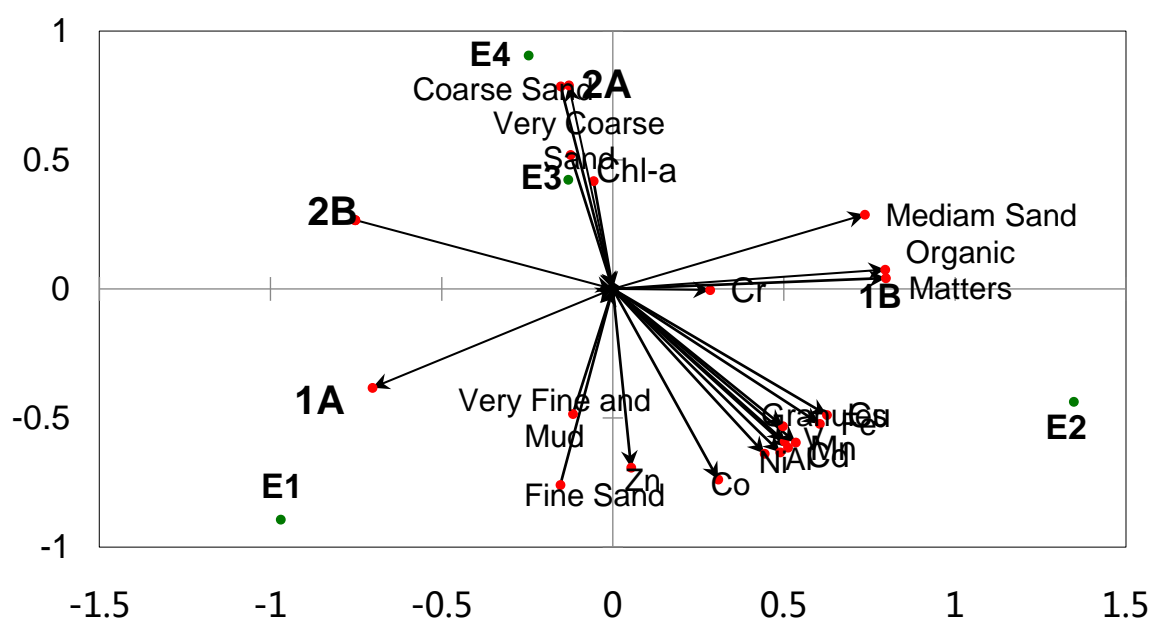

Figure 9. RDA tri-plot illustrating the similarities between the feeding types and the environmental factors found in the Estuary. The Tri-plot describes $99.86 \%$ of the variation with $66.93 \%$ described on the first axis and $32.93 \%$ on the second axis.

The higher diversity and density of nematodes at sites E3 and E4 were attributed to sediment particle size such as Coarse Sand, Very Coarse Sand and Chlorophyll-a because they had a strong correlation with nematode feeding types $2 \mathrm{~A}$ and $2 \mathrm{~B}$.

Another strong correlation was observed between very fine sand, fine sand and Zinc with nematodes feeding types $1 \mathrm{~A}$.

\subsection{Environmental Factors and Nematodes Communities}

The BIOENV analysis indicated that although other environmental factors correlated with nematodes diversity, Nitrates $\left(\mathrm{NO}_{3}\right)$, Very Coarse sand, Coarse Sand, and Fine Sand were the most significant $(\mathrm{Rho}=0.693 ; \mathrm{p}<0.05)$ environmental variables that structure nematodes community in the estuary especially when all environmental variables were combined (Table 3). [22] [49] [50] indicated that within an area of uniform salinity, grain size of sediments is a dominant factor in determining the composition of nematodes communities.

According to [51] sediments particle size such as grain size, organic content, and Chl- $a$ are other important factors that contribute to the distribution and buildup of nematodes in estuarine environment. Similar findings were obtained in a study conducted in the Swartkops River in South Africa [15] where sediment particle size was found to influence nematodes density, and the number of nematodes was low at sites dominated by both finer, and coarse sands. In another study conducted by [52] nematodes density and diversity were found to be structured by coarse sediments. [53] also found that the diversity of nematodes was high at the sandiest station and low at the siltiest station in a study conducted in Northumberland coast (Britain). These findings were also supported by [54] [55] who also found that density and diversity of marine nematodes increase with increase sediment grain size. 
Table 3. Summary of BIOENV analysis indicating the environmental factors influencing nematode structures.

\begin{tabular}{ccc}
\hline & Environmental Variables & Correlation or Rho \\
\hline Combined & Nitrate $\left(\mathrm{NO}_{3}\right)$, Very Coarse Sand, Coarse Sand and Fine Sand & 0.693 \\
\hline
\end{tabular}

\section{Conclusion}

Nematode diversity and density decrease with a decrease in salinity gradients in the study. Sites E2 and E1 were found to be the polluted sites with higher concetration of metals and organic matters. Nematodes genera such as Terschellingia, Theristus and Halalaimus were also found to be dominant at these sites E2 and E1. The positive correlation between nematodes genera such as Terschellingia, Theristus and Halalaimus with metals such as Cadmium, Colbat, Chromium, Copper, Iron, Manganese, Nickel, Vadium, Zinc, and Aluminium indicated that these nematode genera can be pollution indicators in the estuarine environments. A combination of Maturity Index, Shannon-Diversity Index and c-p values was good tool in identifying polluted sites in the study. It is recommended that further studies are done along the Mozambican Coast to identify nematodes that can be used as pollution indicators.

\section{Acknowledgements}

I would like to send my gratitude to the Inkomati-Usuthu Catchment Management Agency which is the first CMA to be established in South Africa for their funding for this study. I would also wish to thank my supervisor Dr. T Gyedu-Ababio for his advice and assistance in identification of meiofauna and nematodes during the study.

\section{Conflicts of Interest}

The authors declare no conflicts of interest regarding the publication of this paper.

\section{References}

[1] Webber, C.L. (1996) Response of Kenaf to Nitrogen Fertilization. Part III. In: Janick, J., Ed., Progress in New Crops, ASHS Press, Arlington, 404-408.

[2] Hameedi, M.J. (1997) Strategy for Monitoring the Environment in the Coastal Zone. In: Haq, B.U., Haq, S.M., Kullenberg, G. and Stel, J.H., Eds., Coastal Zone Management Imperative for Maritime Developing Nations, Springer, Dordrecht, 111-142. https://doi.org/10.1007/978-94-017-1066-4_8

[3] Sengo, D.J. (2003) Effects of Water Management in Incomati River Basin into Estuarine System: A Downstream Perspective of Socio-Economic Demands from the Estuarine Services. M.Sc. Thesis, UNESCO-IHE, Delft.

[4] Díaz, R.J. and Rosenberg, R. (2008) Spreading Dead Zones and Consequences for Marine Ecosystems. Science, 321, 926-929. https://doi.org/10.1126/science.1156401

[5] Vanaverbeke, J., Steyaert, M., Vanreusel, A. and Vincx, M. (2003) Nematode Biomass Spectra as Descriptors of Functional Changes to Human and Natural Impact. 
Marine Ecology Progress Series, 249, 157-170. https://doi.org/10.3354/meps249157

[6] Vanaverbeke, J., Soetaert, K. and Vincx, M. (2004) Changes in Morphometric Characteristics of Nematode Communities during a Spring Phytoplankton Bloom Deposition. Marine Ecology Progress Series, 273, 139-146.

https://doi.org/10.3354/meps273139

[7] Kennedy, A.D. and Jacoby, C.A. (1999) Biological Indicators of Marine Environmental Health: Meiofauna-A Neglected Benthic Component? Environmental Monitoring and Assessment, 54, 47-68. https://doi.org/10.1023/A:1005854731889

[8] Schratzberger, M., Gee, J.M., Rees, H.L., Boyd, S.E. and Wall, C.M. (2000) The Structure and Taxonomic Composition of Sublittoral Meiofauna Assemblages as an Indicator of the Status of Marine Environments. Journal of the Marine Biological Association of the United Kingdom, 80, 969-980.

https://doi.org/10.1017/S0025315400003039

[9] Platt, H.M., Shaw, K.M. and Lambshead, P.J.D. (1984) Nematode Species Abundance Patterns and Their Use in the Detection of Environmental Perturbations. Hydrobiologia, 118, 59-66. https://doi.org/10.1007/BF00031788

[10] Heip, C., Basford, D., Craeymeersch, J.A., Dewarumez, J.M., Dorjes, J., de Wilde, P., Duineveld, G., Eleftheriou, A., Herman, P.M.J., Niermann, U., Kingston, P., Kunitzer, A., Rachor, E., Rumohr, H., Soetaert, K. and Soltwedel, T. (1992) Trends in Biomass, Density and Diversity of North Sea Macrofauna. ICES Journal of Marine Science, 49, 13-22. https://doi.org/10.1093/icesjms/49.1.13

[11] Heip, C., Vincx, M. and Vranken, G. (1985) The Ecology of Marine Nematodes. Oceanography and Marine, 23, 399-489.

[12] Yodnarasri, S., Montani, S., Tada, K., Shibanuma, S. and Yamada, T. (2008) Is There Any Seasonal Variation in Marine Nematodes within the Sediments of the Intertidal Zone? Marine Pollution Bulletin, 57, 149-154. https://doi.org/10.1016/j.marpolbul.2008.04.016

[13] Adão, H., Alves, A.S., Patrício, J., Neto, J.M., Costa, M.J. and Marques, J.C. (2009) Spatial Distribution of Subtidal Nematoda Communities along the Salinity Gradient in Two Southern European Estuaries. Acta Oecologica, 35, 287-300.

https://doi.org/10.1016/j.actao.2008.11.007

[14] Hourston, M., Potter, I.C., Warwick, R.M., Valesini, F.J. and Clarke, K.R. (2009) Spatial and Seasonal Variations in the Ecological Characteristics of the Free-Living Nematode Assemblages in a Large Microtidal Estuary. Estuarine, Costal and Shelf Science, 82, 309-322. https://doi.org/10.1016/j.ecss.2009.01.018

[15] Gyedu-Ababio, T.K., Furstenberg, J.P., Baird, D. and Vanreusel, A. (1999) Nematodes as Indicators of Pollution: A Case Study from the Swartkops River System, South Africa. Hydrobiologia, 397, 155-169.

https://doi.org/10.1023/A:1003617825985

[16] Gyedu-Ababio, T.K. and Baird, D. (2006) Response of Meiofauna and Nematode Communities to Increased Levels of Contaminants in a Laboratory Microcosm Experiment. Ecotoxicology \& Environmental Safety, 63, 443-450.

https://doi.org/10.1016/j.ecoenv.2005.01.010

[17] Gyedu-Ababio, T. (2011) Pollution Status of Two River Estuaries in the Eastern Cape, South Africa, Based on Benthic Meiofauna Analyses. Journal of Water Resource and Protection, 3, 473-486. https://doi.org/10.4236/jwarp.2011.37057

[18] Snelgrove, P.V.R. and Butman, C.A. (1994) Animal-Sediment Relationship Revisited: Cause versus Effect. Oceanography of Marine Biology Annual Review, 32, 111-177. 
[19] Danovaro, R. and Gambi, C. (2002) Biodiversity and Trophic Structure of Nematode Assemblages in Seagrass Systems: Evidence for a Coupling with Changes in Food Availability. Marine Biology, 141, 667-677. https://doi.org/10.1007/s00227-002-0857-y

[20] Forster, S.J. (1998) Osmotic Stress Tolerance and Osmoregulation of Intertidal and Subtidal Nematodes. Journal of Experimental Marine Biology and Ecology, 224, 109-125. https://doi.org/10.1016/S0022-0981(97)00192-5

[21] Moens, T. and Vincx, M. (2000) Temperature, Salinity and Food Thresholds in Two Brackish-Water Bacterivorous Nematode Species: Assessing Niches from Food Absorption and Respiration Experiments. Journal of Experimental Marine Biology and Ecology, 243, 137-154. https://doi.org/10.1016/S0022-0981(99)00114-8

[22] Ward, A.R. (1975) Studies on the Sublittoral Free-Living Nematodes of Liverpool Bay, II. Influence of Sediment Composition on the Distribution of Marine Nematodes. Marine Biology, 30, 217-225. https://doi.org/10.1007/BF00390744

[23] Vincx, M., Meire, P. and Heip, C. (1990) The Distribution of Nematode Communities in the Southern Bight of the North Sea. Cashier of Biological Marine, 31, 107-129.

[24] Vanaverbeke, J., Gheskiere, T., Steyaert, M. and Vincx, M. (2002) Nematode Assemblages from Subtidal Sandbanks in the Southern Bight of the North Sea: Effect of Small Sedimentological Differences. Journal of Sea Research, 48, 197-207. https://doi.org/10.1016/S1385-1101(02)00165-X

[25] Vanaverbeke, J., Gheskiere, T. and Vincx, M. (2000) The Meiobenthos of Subtidal Sandbanks on the Belgian Continental Shelf (Southern Bight of the North Sea). Es tuarine, Coastal and Shelf Science, 51, 637-649. https://doi.org/10.1006/ecss.2000.0703

[26] Riddell, E., Pollard, S., Mallory, S. and Sawunyama, T. (2014) A Methodology for Historical Assessment of Compliance with Environmental Water Allocations: Lessons from the Crocodile (East) River, South Africa. Journal of Hydrological Science, 59, 831-843. https://doi.org/10.1080/02626667.2013.853123

[27] Heip, C., Vincx, M., Smol, N. and Vranken, G. (1982) The Systematics and Ecology of Free-Living Marine Nematodes. Helminthological Abstracts Series B, Plant Nematology, 51, 1-31.

[28] Smol, N., Willems, K.A., Govaere, J.C. and Sandee, A.J.J. (1994) Composition, Distribution and Biomass of Meiobenthos in the Oosterschelde Estuary (SW Netherlands). Hydrobiologia, 282, 197-217. https://doi.org/10.1007/BF00024631

[29] Fleeger, J.W., Shirley, T.C. and McCall, J.N. (1995) Fine-Scale Vertical Profiles of Meiofauna in Muddy Subtidal Sediments. Canadian Journal of Zoology, 73, 1453-1460. https://doi.org/10.1139/z95-171

[30] Soltwedel, T. (1997) Meiobenthos Distribution Pattern in the Tropical East Atlantic: Indication for Fractionated Sedimentation of Organic Matter to the Sea Floor? Marine Biology, 129, 747-756. https://doi.org/10.1007/s002270050217

[31] Anderson, R.O. (1959) A Modified Flotation Technique for Sorting Bottom Fauna Samples. Limnology and Oceanography, 4, 223-225. https://doi.org/10.4319/lo.1959.4.2.0223

[32] Heip, C., Smol, N. and Hautekiet, W. (1974) A Rapid Method of Extracting Meiobenthic Nematodes and Copepods from Mud and Detritus. Marine Biology, 28, 79-81. https://doi.org/10.1007/BF00389120

[33] Esteves, A.M. and Da Silva, V.M.A.P. (1998) The Behavior of Sugar Flotation Technique in Meiofauna Extraction from Different Sand Types. Tropical Ecology, 39, 
283-284

[34] Giere, O. (1993) Meiobenthology: The Microscopic Fauna in Aquatic Sediments. Springer-Verlag, New York. https://doi.org/10.1007/978-3-662-02912-1

[35] Platt, H.M. and Warwick, R.M. (1988) Free-Living Marine Nematodes, Part II: British Chromadorids. Cambridge University Press, Cambridge.

[36] Wieser, W. (1953) The Relationship between Oral Cavity Shape, Nutrition Meadow and 1000 Occurrences in Free-Living Marine Nematodes. Archive for Zoology, 4, 439-484.

[37] Parker, J.G. (1983) A Comparison of Methods Used for the Measurement of Organic Matter in Sediments. Chemistry and Ecology, 1, 201-209. https://doi.org/10.1080/02757548308070802

[38] Buchanan, J.B. (1971) Measurement of the Physical and Chemical Environment. In: Holme, N.A. and McIntyre, A.D., Eds., Methods for the Study of Marine Benthos, Blackwell Scientific Publications, Oxford, UK.

[39] Lorenzen, C. and Jeffrey, J. (1980) Determination of Chlorophyll in Seawater. UNESCO Technical Papers in Marine Sciences, 35, 1-20.

[40] Bongers, T. (1990) The Maturity Index: An Ecological Measure of Environmental Disturbance Based on Nematode Species Composition. Oecologia, 83, 14-19. https://doi.org/10.1007/BF00324627

[41] Bongers, T., Alkemade, R. and Yeates, G.W. (1991) Interpretation of Disturbance-Induced Maturity Decrease in Marine Nematode Assemblages by Means of Maturity Index. Marine Ecological Progress Series, 76, 135-142. https://doi.org/10.3354/meps076135

[42] Clarke, K.R. and Gorley, R.N. (2006) PRIMER v6: User Manual Tutorial. PRIMER-E Ltd., Plymouth, UK.

[43] Clarke, K.R. and Ainsworth, M. (1993) A Method of Linking Multivariate Community Structure to Environmental Variables. Marine Ecological Progress Series, 92, 205-219. https://doi.org/10.3354/meps092205

[44] Patrício, J., Neto, J.M., Teixeira, H., Salas, F. and Marques, J.C. (2009) The Robustness of Ecological Indicators to Detect Long-Term Changes in the Macrobenthos of Estuarine Systems. Marine Environmental Research, 68, 25-36. https://doi.org/10.1016/j.marenvres.2009.04.001

[45] Alves, A.S., Adãob, H., Ferrero, T.J., Marques, J.C., Costad, M.J. and Patrício, J. (2013) Benthic Meiofauna as Indicator of Ecological Changes in Estuarine Ecosystems: The Use of Nematodes in Ecological Quality Assessment. Ecological Indicators, 24, 462-475. https://doi.org/10.1016/j.ecolind.2012.07.013

[46] Lampadariou, N., Austen, M.C., Robertson, N. and Vlachonis, G. (1997) Analysis of Meiobenthic Community Structure in Relation to Pollution and Disturbance in Iraklion Harbour, Greece. Vie et Milieu, 47, 9-24.

[47] Liu, X., Xu, M., Hua, E. and Zhang, Z. (2016) Biodiversity of Free-Living Nematodes in the Southern Yellow Sea, China. Journal of Ocean University of China, 15, 1-10. https://doi.org/10.1007/s11802-016-2722-5

[48] Moreno, M., Ferrero, T.J., Gallizia, I., Vezzulli, L., Albertelli, G. and Fabiano, M. (2008) An Assessment of the Spatial Heterogeneity of Environmental Disturbance within an Enclosed Harbour through the Analysis of Meiofauna and Nematode Assemblages. Estuarine, Coastal and Shelf Science, 77, 565-576. https://doi.org/10.1016/j.ecss.2007.10.016

[49] Wieser, W. (1960) Benthic Studies in Buzzards Bay. Part II. The Meiofauna. Lim- 
nology and Oceanography, 5, 121-137. https://doi.org/10.4319/lo.1960.5.2.0121

[50] Tietjen, J.H. (1977) Population Distribution and Structure of the Free-Living Nematodes of Long Island Sound. Marine Biology, 43, 123-136.

https://doi.org/10.1007/BF00391260

[51] Levin, L.A., Huggett, C.L. and Wishner, K.F. (1991) Control of Deep Sea Benthic Community Structure by Oxygen and Organic-Matter Gradients in the Eastern Pacific Ocean. Journal of Marine Research, 49, 763-800. https://doi.org/10.1357/002224091784995756

[52] De Beer, J.D., Dryer, J. and Loubser, C. (2005) Environmental Issues and Risks. In: Loubser, C.P., Ed., Environmental Education, Some South African Perspectives, Van Schaik Publishers, Pretoria.

[53] Warwick, R.M. and Buchanan, J.B. (1971) The Meiofauna off the Coast of Northumberland. II. Seasonal Stability of the Nematode Population. Journal of the Marine Biological Association of the United Kingdom, 51, 355-362. https://doi.org/10.1017/S0025315400031830

[54] Vanaverbeke, J., Merckx, B., Degraer, S. and Vincx, M. (2011) Sediment-Related Distribution Patterns of Nematodes and Macrofauna: Two Sides of the Benthic Coin? Marine Environmental Research, 71, 31-40. https://doi.org/10.1016/j.marenvres.2010.09.006

[55] Fonseca, V.G., Carvallo, G.R., Quince, C., Johnson, H.F., Neill, S.P., Lambshead, J.D., Thomas, W.K., Power, D.M. and Creer, S. (2014) Metagenetic Analysis of Patterns of Distribution and Diversity of Marine Meiobenthic Eukaryotes. Global Ecology and Biogeography, 23, 1293-1302. https://doi.org/10.1111/geb.12223 


\section{Appendix A}

Table A1. Feeding types, c-p values, salinity ranged, and Nematodes Genera identified in the Incomati River Estuary from June 2017 to April 2018.

\begin{tabular}{|c|c|c|c|c|c|c|c|c|c|c|c|c|c|c|c|c|c|c|c|c|c|c|c|c|c|c|}
\hline \multirow{4}{*}{$\begin{array}{l}\text { NEMATODE } \\
\text { GENUS }\end{array}$} & \multirow{4}{*}{ 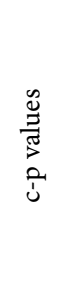 } & \multirow{4}{*}{ 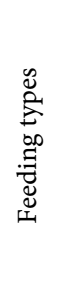 } & \multicolumn{6}{|c|}{ E1 } & \multicolumn{6}{|c|}{ E2 } & \multicolumn{6}{|c|}{ E3 } & \multicolumn{6}{|c|}{ E4 } \\
\hline & & & \multicolumn{24}{|c|}{ Salinity range amongst the sites } \\
\hline & & & \multicolumn{6}{|c|}{$0-3$ NST } & \multicolumn{6}{|c|}{3 - 5 NST } & \multicolumn{6}{|c|}{$5-18$ NST } & \multicolumn{6}{|c|}{$18-26$ NST } \\
\hline & & & 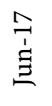 & 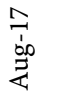 & 今 & 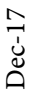 & $\begin{array}{l}\infty \\
\overrightarrow{1} \\
\overrightarrow{0} \\
\dot{1}\end{array}$ & 我 & $\stackrel{=}{\stackrel{1}{g}}$ & 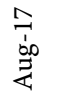 & जัञ & $\begin{array}{l}\hat{y} \\
\dot{u}\end{array}$ & $\begin{array}{l}\infty \\
\stackrel{1}{0} \\
\text { के }\end{array}$ & $\begin{array}{l}\infty \\
\stackrel{\overrightarrow{2}}{4} \\
\frac{1}{4}\end{array}$ & 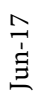 & $\frac{1}{3}$ & 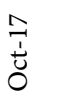 & $\begin{array}{l}\hat{u} \\
\dot{u}\end{array}$ & $\begin{array}{l}\infty \\
\stackrel{1}{0} \\
\text { 离 }\end{array}$ & $\begin{array}{l}\infty \\
\stackrel{\vec{\omega}}{4} \\
\dot{4}\end{array}$ & $\stackrel{\equiv}{\grave{\Xi}}$ & 今ે & $\stackrel{1}{\stackrel{1}{\Delta}}$ & $\begin{array}{l}\bar{y} \\
\dot{u} \\
\dot{0}\end{array}$ & $\begin{array}{l}\infty \\
\stackrel{1}{0} \\
\text { 0े }\end{array}$ & 交 \\
\hline Adoncholaimus & 3 & $2 \mathrm{~B}$ & 13 & 12 & 15 & 3 & 0 & 0 & 0 & 0 & 1 & 0 & 0 & 0 & 0 & 1 & 2 & 10 & 11 & 0 & 0 & 6 & 0 & 1 & 2 & 0 \\
\hline Aegialoalaimus & 4 & $1 \mathrm{~A}$ & 3 & 0 & 0 & 4 & 2 & 0 & 0 & 0 & 2 & 0 & 0 & 0 & 0 & 0 & 3 & 0 & 10 & 0 & 0 & 11 & 12 & 6 & 0 & 8 \\
\hline Anoplostoma & 2 & $1 \mathrm{~B}$ & 10 & 15 & 0 & 9 & 13 & 11 & 0 & 0 & 2 & 0 & 0 & 0 & 2 & 0 & 0 & 6 & 0 & 0 & 0 & 9 & 3 & 6 & 4 & 3 \\
\hline Axonolaimus & 2 & $1 \mathrm{~B}$ & 3 & 15 & 16 & 12 & 3 & 26 & 0 & 10 & 9 & 10 & 10 & 20 & 0 & 0 & 0 & 0 & 0 & 0 & 0 & 11 & 0 & 10 & 4 & 4 \\
\hline Batylaiumus & 2 & $1 \mathrm{~B}$ & 0 & 0 & 0 & 0 & 0 & 0 & 0 & 0 & 0 & 0 & 0 & 0 & 10 & 0 & 0 & 11 & 0 & 50 & 0 & 0 & 0 & 0 & 0 & 4 \\
\hline Camacolaimus & 3 & $2 \mathrm{~A}$ & 0 & 0 & 0 & 0 & 0 & 8 & 3 & 2 & 0 & 1 & 0 & 0 & 0 & 0 & 0 & 0 & 0 & 2 & 0 & 0 & 0 & 0 & 0 & 0 \\
\hline Cephalainticoma & 2 & $2 \mathrm{~A}$ & 0 & 0 & 0 & 0 & 0 & 0 & 0 & 0 & 0 & 0 & 0 & 0 & 2 & 0 & 0 & 0 & 0 & 0 & 0 & 0 & 0 & 2 & 0 & 0 \\
\hline Daptonema & 3 & $1 \mathrm{~B}$ & 0 & 3 & 1 & 2 & 0 & 0 & 1 & 1 & 1 & 10 & 3 & 0 & 10 & 0 & 0 & 9 & 5 & 5 & 10 & 0 & 0 & 6 & 12 & 2 \\
\hline Dichromadora & 2 & $2 \mathrm{~A}$ & 0 & 0 & 0 & 0 & 0 & 0 & 0 & 0 & 0 & 0 & 0 & 0 & 3 & 0 & 0 & 0 & 20 & 0 & 12 & 2 & 0 & 3 & 10 & 8 \\
\hline Dolicholaimus & 2 & $2 \mathrm{~B}$ & 0 & 0 & 0 & 0 & 0 & 0 & 0 & 0 & 0 & 0 & 0 & 0 & 4 & 0 & 1 & 0 & 0 & 0 & 0 & 0 & 0 & 2 & 10 & 0 \\
\hline Enoplus & 5 & $2 \mathrm{~B}$ & 0 & 0 & 0 & 0 & 0 & 0 & 0 & 0 & 0 & 2 & 0 & 0 & 6 & 0 & 0 & 0 & 0 & 0 & 0 & 3 & 0 & 0 & 0 & 0 \\
\hline Filoncholaimus & 4 & $2 \mathrm{~B}$ & 0 & 0 & 0 & 0 & 0 & 0 & 0 & 0 & 0 & 4 & 0 & 0 & 6 & 20 & 5 & 0 & 9 & 0 & 2 & 0 & 0 & 0 & 0 & 0 \\
\hline Halalaimus & 4 & $1 \mathrm{~A}$ & 0 & 0 & 0 & 0 & 0 & 0 & 0 & 0 & 0 & 0 & 0 & 0 & 5 & 0 & 0 & 2 & 3 & 0 & 0 & 3 & 0 & 0 & 2 & 0 \\
\hline Haliplectus & 2 & $1 \mathrm{~A}$ & 23 & 29 & 35 & 34 & 54 & 55 & 0 & 3 & 0 & 5 & 0 & 0 & 0 & 0 & 0 & 1 & 0 & 0 & 0 & 0 & 0 & 0 & 0 & 0 \\
\hline Leptolaimus & 2 & $1 \mathrm{~A}$ & 0 & 0 & 0 & 0 & 0 & 0 & 0 & 0 & 0 & 0 & 0 & 0 & 3 & 0 & 1 & 3 & 0 & 0 & 1 & 5 & 3 & 3 & 0 & 0 \\
\hline Metachromadora & 3 & $2 \mathrm{~A}$ & 0 & 0 & 0 & 0 & 0 & 0 & 0 & 0 & 0 & 0 & 0 & 0 & 0 & 8 & 0 & 0 & 0 & 5 & 5 & 7 & 10 & 4 & 8 & 0 \\
\hline Metacyatholaimus & 3 & $2 \mathrm{~A}$ & 0 & 0 & 0 & 0 & 0 & 0 & 0 & 0 & 2 & 1 & 0 & 0 & 0 & 0 & 0 & 0 & 0 & 0 & 0 & 0 & 0 & 0 & 0 & 0 \\
\hline Microlaimus & 2 & $2 \mathrm{~A}$ & 0 & 0 & 0 & 0 & 0 & 0 & 0 & 0 & 2 & 0 & 0 & 0 & 3 & 2 & 1 & 1 & 3 & 0 & 1 & 6 & 5 & 7 & 2 & 0 \\
\hline Monhystera & 2 & $1 \mathrm{~B}$ & 0 & 0 & 0 & 0 & 0 & 0 & 0 & 0 & 6 & 0 & 0 & 0 & 0 & 2 & 2 & 0 & 0 & 0 & 5 & 2 & 0 & 7 & 3 & 0 \\
\hline Neochomadora & 3 & $2 \mathrm{~A}$ & 0 & 0 & 0 & 0 & 0 & 0 & 0 & 0 & 0 & 0 & 0 & 0 & 0 & 3 & 7 & 6 & 9 & 4 & 0 & 0 & 0 & 13 & 0 & 0 \\
\hline Oncholaimellus & 3 & $2 \mathrm{~B}$ & 0 & 0 & 0 & 0 & 0 & 0 & 0 & 0 & 0 & 0 & 0 & 0 & 0 & 1 & 2 & 1 & 0 & 0 & 0 & 2 & 0 & 0 & 0 & 0 \\
\hline Oxystomina & 4 & $1 \mathrm{~A}$ & 0 & 0 & 6 & 0 & 0 & 0 & 0 & 0 & 0 & 0 & 0 & 0 & 0 & 20 & 10 & 9 & 0 & 8 & 3 & 0 & 0 & 0 & 0 & 0 \\
\hline Paracyatholaimus & 2 & $2 \mathrm{~A}$ & 0 & 0 & 0 & 0 & 0 & 0 & 0 & 0 & 0 & 0 & 0 & 0 & 0 & 0 & 0 & 0 & 2 & 0 & 4 & 10 & 0 & 0 & 13 & 0 \\
\hline Paramonohystera & 4 & $1 \mathrm{~B}$ & 0 & 4 & 3 & 4 & 13 & 0 & 14 & 4 & 9 & 6 & 8 & 0 & 1 & 19 & 12 & 5 & 2 & 3 & 2 & 1 & 0 & 3 & 4 & 1 \\
\hline Pomponema & 3 & $2 \mathrm{~B}$ & 0 & 0 & 0 & 0 & 0 & 0 & 0 & 0 & 0 & 0 & 0 & 0 & 0 & 0 & 3 & 2 & 5 & 0 & 6 & 0 & 0 & 2 & 4 & 32 \\
\hline Pseudochromadora & 3 & $2 \mathrm{~A}$ & 0 & 0 & 0 & 0 & 0 & 0 & 0 & 0 & 0 & 1 & 0 & 0 & 4 & 0 & 10 & 7 & 5 & 2 & 2 & 1 & 12 & 0 & 0 & 0 \\
\hline Rhabditis & 1 & $1 \mathrm{~A}$ & 1 & 3 & 4 & 8 & 3 & 0 & 0 & 0 & 0 & 0 & 0 & 0 & 0 & 0 & 0 & 3 & 0 & 5 & 6 & 0 & 2 & 0 & 0 & 4 \\
\hline Sabatiera & 2 & $1 \mathrm{~B}$ & 0 & 0 & 0 & 4 & 1 & 0 & 8 & 3 & 0 & 0 & 0 & 0 & 5 & 12 & 14 & 20 & 0 & 0 & 10 & 0 & 5 & 3 & 0 & 19 \\
\hline Scaptrella & 2 & $2 \mathrm{~B}$ & 0 & 0 & 0 & 0 & 0 & 0 & 0 & 0 & 0 & 0 & 0 & 0 & 0 & 0 & 0 & 0 & 0 & 0 & 3 & 4 & 6 & 5 & 0 & 0 \\
\hline Spirinia & 3 & $2 \mathrm{~A}$ & 0 & 0 & 0 & 0 & 0 & 0 & 0 & 0 & 0 & 0 & 0 & 0 & 0 & 0 & 0 & 0 & 0 & 0 & 3 & 1 & 0 & 2 & 3 & 5 \\
\hline
\end{tabular}




\section{Continued}

\begin{tabular}{ccccccccccccccccccccccccccccc}
\hline Synonchium & 3 & $2 \mathrm{~B}$ & 0 & 8 & 12 & 2 & 4 & 0 & 6 & 6 & 0 & 0 & 0 & 0 & 0 & 0 & 0 & 0 & 0 & 0 & 0 & 0 & 0 & 0 & 0 & 0 \\
Terschellingia & 3 & $1 \mathrm{~B}$ & 2 & 5 & 2 & 8 & 4 & 0 & 56 & 56 & 50 & 30 & 52 & 41 & 0 & 4 & 9 & 0 & 0 & 0 & 10 & 6 & 10 & 10 & 8 & 0 \\
Theristus & 2 & $1 \mathrm{~B}$ & 6 & 3 & 3 & 4 & 0 & 0 & 12 & 10 & 13 & 31 & 25 & 34 & 36 & 3 & 5 & 4 & 0 & 1 & 0 & 5 & 10 & 0 & 0 & 1 \\
Viscocia & 3 & $2 \mathrm{~B}$ & 1 & 3 & 3 & 6 & 5 & 0 & 0 & 5 & 3 & 0 & 2 & 5 & 0 & 5 & 12 & 0 & 16 & 15 & 16 & 3 & 12 & 6 & 11 & 9 \\
Xyala & 3 & $1 \mathrm{~B}$ & 0 & 0 & 0 & 0 & 0 & 0 & 0 & 0 & 0 & 0 & 0 & 0 & 0 & 0 & 1 & 0 & 0 & 0 & 0 & 2 & 10 & 1 & 0 & 0 \\
\hline
\end{tabular}

